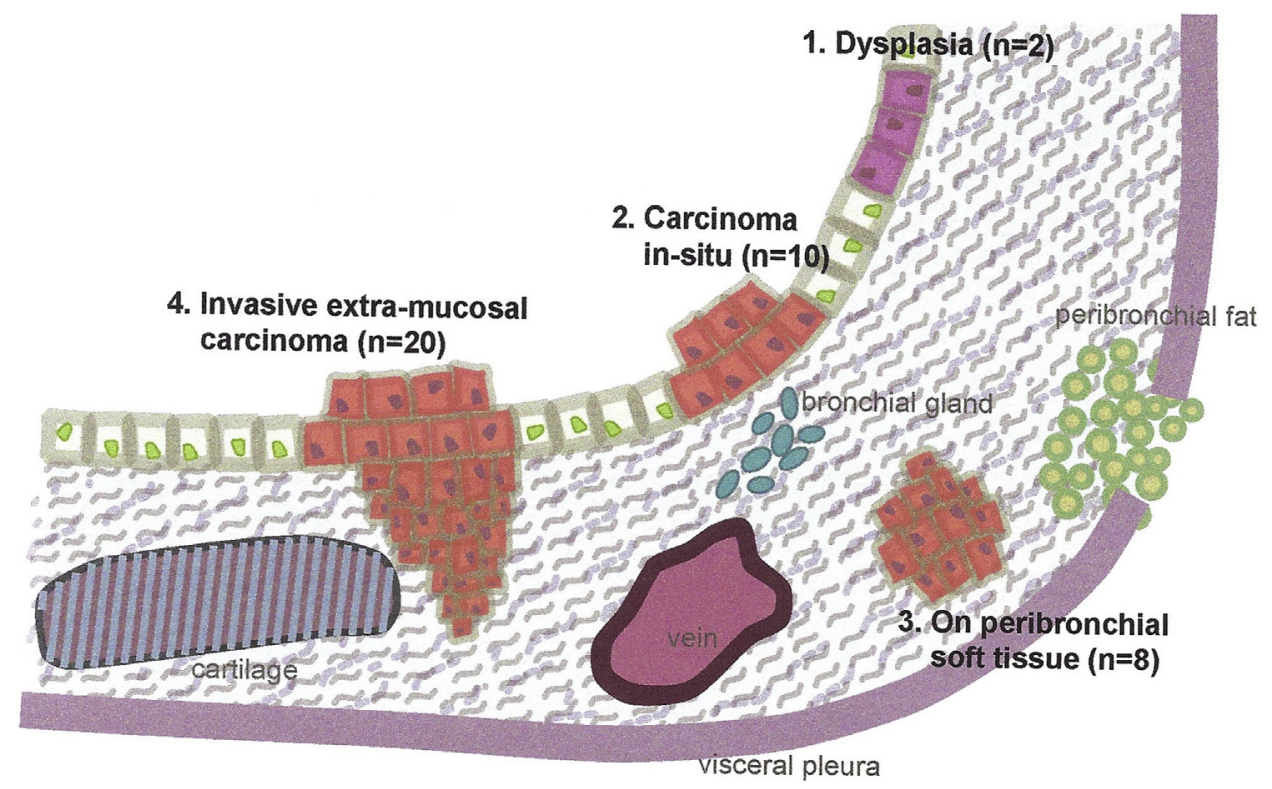

FIGURE 1. Different sites of involvement of the bronchial section margins.

2. Massard G, Kessler R, Gasser B, Ducrocq X, Elia S, Gouzou S, et al. Local control of disease and survival following bronchoplastic lobectomy for non-small cell lung cancer. Eur J Cardiothorac Surg. 1999;16: 276-82.

3. Massard G, Doddoli C, Gasser B, Ducrocq X, Kessler R, Schumacher C, et al. Prognostic implications of a positive bronchial resection margin. Eur J Cardiothorac Surg. 2000;17:557-65.
4. Hong TH, Kim J, Shin S, Kim HK, Choi SY, Zo JI, et al. Clinical outcomes of microscopic residual disease after bronchial sleeve resection for non-small cell lung cancer. J Thorac Cardiovasc Surg. 2021;161:267-77.e9.

5. Edwards JG, Chansky K, Van Schil P, Nicholson AG, Boubia S, Brambilla E, et al. The IASLC lung cancer staging project: analysis of resection margin status and proposals for residual tumor descriptors for non-small cell lung cancer. J Thorac Oncol. 2020:15:344-59.

\title{
Commentary: Absence of evidence is not evidence of absence
}

Vignesh Raman, MD, and Oliver K. Jawitz, MD

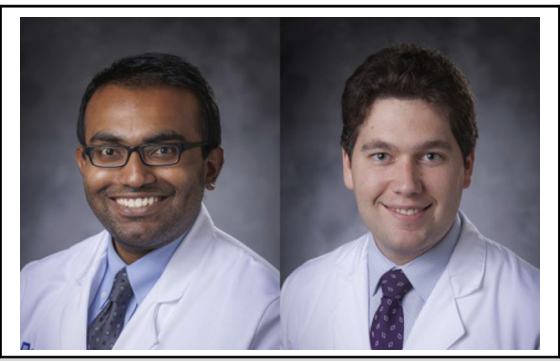

Vignesh Raman, MD, and Oliver K. Jawitz, MD

CENTRAL MESSAGE

Although microscopically posi-

tive bronchial margins were not associated with worse survival in this study, only 28 patients had invasion at the margin, making the data difficult to interpret. 
Hong and colleagues ${ }^{1}$ report a retrospective cohort study that characterizes the survival of 536 patients with a negative (R0) or microscopically positive (R1) bronchial resection margin after a sleeve resection for non-small cell lung cancer. They describe that overall and recurrence-free survival were not significantly compromised for 12 patients with dysplasia or carcinoma in situ and 28 patients with invasion at the margin in comparison with those with complete resection. They further demonstrate no meaningful interaction between margin status and receipt of adjuvant therapy.

Hong and colleagues' study ${ }^{1}$ is primarily valuable for reporting the outcomes of a substantial cohort of patients who underwent a sleeve resection. Their findings about the likelihood and identity of recurrence following the breadth of R1 manifestations and the concordance in margin status between intraoperative frozen evaluation and final pathology are particularly important for clinicians who seek data to guide decisions for the important question of how an intraoperative microscopic margin should be addressed during sleeve resection and if completion pneumonectomy would necessarily mitigate the risk of recurrence in patients who can tolerate it.

Unfortunately, absence of evidence does not equate to an evidence of absence. ${ }^{2}$ The study reports outcomes of merely 28 patients with invasive R1 status, and the lack of significance found in multivariable regression may represent type II error from a small sample size, which the authors acknowledge candidly. We cannot reasonably conclude on the basis of these data that a remnant invasive $\mathrm{R} 1$ bronchial margin is not truly associated with worse survival or that the receipt of adjuvant therapy is not associated with improved survival. Although $78 \%$ of patients with positive margins were identified appropriately in surgery, the authors also do not describe a re-resection pathway that still spares patients a pneumonectomy, which may be preferentially considered. Further, a comparison of outcomes, especially about recurrence patterns, with patients who underwent a pneumonectomy at their institution would have been informative to guide an algorithm after an incomplete sleeve resection.

However, to paraphrase Voltaire, perfect is the enemy of good, and given the rarity of sleeve resections, the authors are to be commended on a detailed, descriptive characterization of outcomes after sleeve resection. In considering the central question of this article, about how patients with an R1 bronchial margin after sleeve resection should be managed, this article's findings about frozen section concordance, short-term postoperative outcomes, and patterns of recurrence may certainly be helpful in at least identification of factors that should be considered in the care of this unique subset of patients.

\section{References}

1. Hong TH, Kim J, Shin S, Kim HK, Choi YS, Zo J, et al. Clinical outcomes of microscopic residual disease after bronchial sleeve resection for non-small cell lung cancer. J Thorac Cardiovasc Surg. 2021;161:267-77.e9.

2. Altman DG, Bland JM. Statistics notes: absence of evidence is not evidence of absence. BMJ. 1995;311:485. 